\title{
Na sala VIP com Jorge Silva Melo e os seus actores
}

\author{
Christine Zurbach
}

\begin{abstract}
Título: Sala VIP. Autor:Jorge Silva Melo. Encenação: Pedro Gil assistido por João Delgado. Cenografia e figurinos: Rita Lopes Alves assistida por Ângela Rocha. Luz: Pedro Domingos assistido por João Chicó. Músico: João Aboim. Intérpretes: Andreia Bento, Maria João Falcão, Elmano Sancho, António Simões e João Pedro Mamede. Produção: Pedro Gil / Artistas Unidos / Culturgest. Local e data de estreia: Teatro da Politécnica, Lisboa, 4 de Setembro de 2013.
\end{abstract}

Jorge Silva Melo é actor, encenador, e realizador de cinema. E hoje também figura entre os dramaturgos com maior reconhecimento no repertório teatral contemporâneo.

Autor de uma dezena de peças, todas encenadas e publicadas, estreou-se na escrita de teatro em 1995, com António, um rapaz de Lisboa, e no ano seguinte produziu uma segunda obra, 0 fim ou tende misericórdia de nós. Nas palavras de Carlos Porto, com estes dois espectáculos, "Jorge Silva Melo está a tornar-se responsável pelo que de mais importante está a acontecer no teatro português dos anos 90" (Porto 1996). De facto, o público e a crítica foram seduzidos por uma concepção formal do texto e por uma abordagem prática da dramaturgia do texto em cena cuja dimensão inovadora "em termos temáticos, estruturais e de construção teatral" (Serôdio 2004: 137) se destacava num panorama teatral algo estagnado.

Até então, ainda era hesitante a introdução no teatro em Portugal de "formas novas". E, à semelhança do que reivindicava Tchekov pela voz de Treplev noutra época de crise do drama, Silva Melo avançou com uma proposta teatral que se distanciava de um teatro "ao gosto" da época - aquilo que ele próprio chamará "espectáculo"

Christine Zurbach

é Professora Associada

com Agregação do

Departamento das Artes

da Universidade de

Évora, onde lecciona nas áreas dos Estudos Teatrais e Estudos de

Tradução e

investigadora do CHAIA (Centro de História de Arte e Investigação Artistica). É ainda tradutora,

dramaturgista, especialista em teatro de marionetas e autora de diversos livros sobre estas temáticas.
(1997: 181). Com essa legítima rejeição, confirmava a função central do texto, claramente entendido como um texto "para" (o) teatro, escrito não para os encenadores mas para os actores. E também com eles. As primeiras peças foram elaboradas em seminários de trabalho com o embrião do grupo que estará na origem dos Artistas Unidos: "O texto é nosso, em bruto" (Melo 1997: 11) como afirma a propósito do processo de escrita de 0 fim, em que também fala da palavra no teatro como algo que "pode ser 'outra palavra'"; "a palavra no teatro pode ser (será?) um imenso silêncio mental" (ibidem). Também escreverá mais tarde sobre o teatro: "esse esplendor da palavra e dos actores" (Melo 2001: 15).

Foi para nos falar dos actores - e à atenção deles em primeiro lugar - que inventou a fábula teatral intitulada não sem humor e alguma (auto)ironia, Sala VIP.

O título evoca de imediato um lugar para elites ou privilegiados, conotado com segurança, conforto e recato. Mas o espectáculo dá-Ihe um sentido não só ambiguo como também contraditório: é nesse espaço que Sala VIP propõe revelar uma verdade do actor, no seu esplendor e na sua miséria, fazendo justiça à paixão indefectivel de Silva Melo pelos seus tão vulneráveis cúmplices. No editorial do primeiro número da revista da companhia Artistas Unidos já o afirmava: "[...] no centro sempre da nossa actividade, que já leva uns anos, estão os actores. Escrevi para eles, escrevi com eles, pensei com eles, traduzi para eles, vivi deles" (Melo 1999: 3). No prefácio à edição da peça 0 navio dos negros afirma: "[...] gosto dos palcos: uns panos, uns trapos, veludos, cadeiras, umas luzes, mais panos, umas madeiras, uns cabos e umas pessoas (vivas por enquanto mas sucedendo-se numa estafeta infinda) a falar. Só gosto de pessoas, só gosto de actores" (Melo 2001: 11).

Esta peça nasce de um diálogo intenso do autor com materiais diversos, que resulta numa composição teatral que Ihes confere uma outra vida. Por exemplo, a sala VIP faz lembrar o espaço raciniano da antecâmara descrito por Barthes, ou o huis clos de muitas obras contemporâneas, mas, em primeiro plano, o que sobressai é uma opção de Silva Melo, "lembrando-(se)" do dramaturgo inglês Terence Rattigan, autor do guião do filme The V.I.P's, em que brilharam Elizabeth Taylor e Richard Burton juntos pela primeira vez.

Os actores que o espectador descobre na Sala VIP são cantores de ópera, que, no caminho para uma (im)provável récita em Filadelfia, ficaram retidos num aeroporto sem que o espectador venha a saber ao certo porquê, e cujas relações se vão extremando e degradando pouco e pouco diante dos nossos olhos. Entre soprano, mezzo, barítono e tenor, assumem nomes de personagens de conhecidissimos libretos do repertório romântico como a Leonora e a Açucena do Trovador de Verdi; ou como Huskymiller, heró tirado da Carmen Jones, versão fílmica por Otto Preminger da Carmen de Bizet, acompanhados pelo indispensável empresário Karsenty Jr., aqui no centro de um enredo amoroso cruel e desesperado, em que o amado é Billy the Kid, jovem amante impiedoso, implacável na afirmação da sua paixão pela vida, como a jovem Manon Lescaut que também habita o texto e desesperou o jovem Des Grieux. 


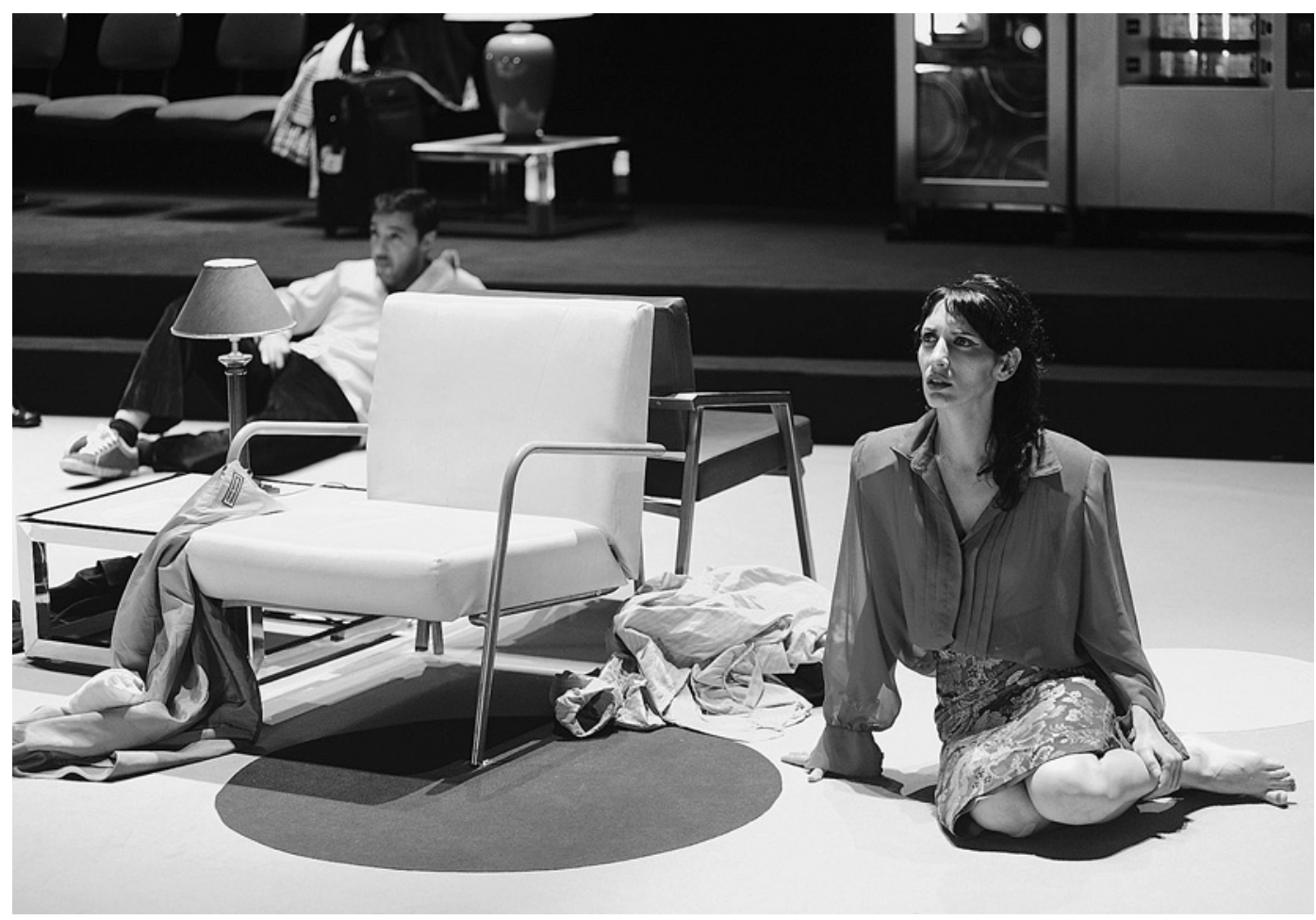

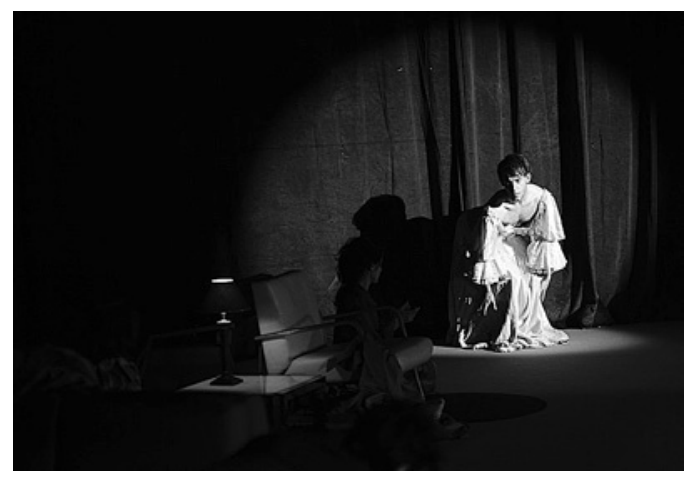

O espaço, citado pelo título, é sobriamente reconstituído pela cenografia, cópia da tipologia impessoal e estereotipada de uma sala de espera, com sofás e máquina distribuidora de snacks. É emoldurado do lado direito do palco, por um pano de veludo azul, evocador do ambiente físico para uma encenação de teatro lírico, e por uma tela-fotografia gigante, ilustrada com peixes, que reenvia para um outro espaço, o de uma discoteca, onde estiveram no passado. É referido com insistência no fluir da conversa, sobretudo em falas de Leonora, com medo do chão de vidro e dos "peixes que andavam por baixo", e que acabará efectivamente por cair no fim do espectáculo. Esse espaço distante acaba por invadir a sala de espera no único momento da peça que traz uma recordação feliz, em que todos se envolvem de corpo e alma numa dança ao som de Mi tierra de Gloria Estefan. Ao fundo, um piano para a música tocada ao vivo por João Aboim, parceiro imprescindivel do quadro imagético e musical do espectáculo que se transformará sucessivamente na "antecamâra do SPA de um hotel de cinco estrelas" e na "sala de espera de uma clínica privada muito moderna" no final da peça.

Expostas na sua fragilidade e vulnerabilidade, as personagens imaginadas por Silva Melo transportam com elas as vidas fora do comum dos amantes de óperas que

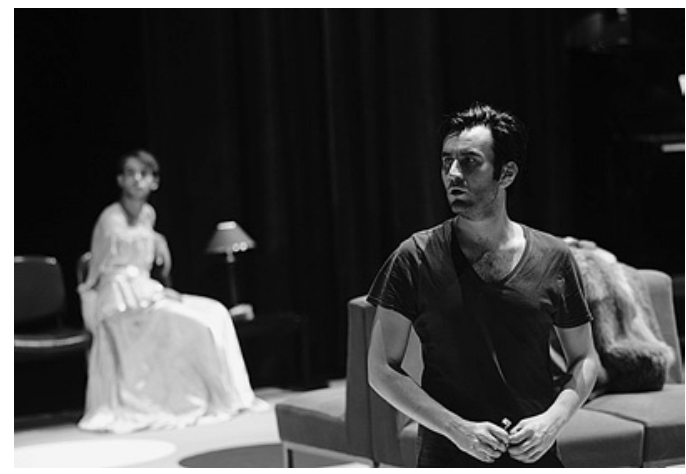

interpretaram, e que contrastam hoje com a vulgaridade das suas carreiras já em declínio. "Estamos a ficar velhos", dizem-nos repetidamente; as suas próprias histórias de vida surgem ao longo dos diálogos em recordações soltas, atiradas ao fio da conversa que ocupa o vazio da espera, mas que mal permitem reconstituir uma biografia. 0 seu mundo, talvez narrado com mais exuberância pela Açucena, comunista de Modena e outrora famosa - "eu a certa altura tinha, [...] sete jardineiros" -, assimilou o da ficção a ponto de comunicarem com falas-citações de árias ou canções, algumas tristes como aquela que Billy the Kid, em nome de um pragmatismo lúcido, insiste em repetir, num quase leitmotiv: "Oh, baby, baby, it's a hard world".

Dando vida à realidade ficcionada que integra como uma segunda pele, a peça multiplica os planos da nossa leitura. As histórias individuais inscrevem-se noutras narrativas, por vezes duplicando-as. Assim, por exemplo, Billy the Kid, como figura da transgressão, surge "esplendidamente vestido de Manon Lescaut, no segundo acto" e transforma a sala de espera num "clube de travestis barato". Desde Pirandello, um autor caro ao dramaturgo, sabe-se que a vida é um teatro e o teatro é a vida...

A caminho de uma cidade além Atlântico, as personagens nesta última peça de Silva Melo são ao $<>\wedge$

Sala VIP, de Jorge Silva Melo, enc. Pedro Gil, Artistas Unidos, 2013 (< João Pedro Mamede; > João Pedro Mamede e Emano Sancho; $\wedge$ António Simão e Maria João Falcão), fot. Jorge Gonçalves. 
Sala VIP.

de Jorge Silva Melo,

enc. Pedro Gil,

Artistas Unidos, 2013

(António Simão),

fot. Jorge Gonçalves. mesmo tempo seres banais e invulgares, que vivem a ansiedade criada por tentativas de comunicação reiteradamente falhadas com o exterior, com chamadas telefónicas sem resposta. 0 espaço é propício a tensões entre esses seres-personagens que preenchem o vazio da espera com palavras que não configuram verdadeiros diálogos. Dizem-se coisas banais, expressão de um quotidiano quase irrisório, com desejos obsessivos, como o de Leonora, de beber um café, ou o de Açucena, de poder comer as tais "bolinhas com Ovomaltine lá dentro". E ainda os desejos repentinos de sexo, interpretados num jogo mecânico sem emoção, que rompe com qualquer realismo; mas também se pergunta, na Canção da mão-de-obra disponivel, "quanto é que tu me pagas", em que a citação brechtiana do tratamento épico da fábula recorda o carácter venal de todos os nossos actos.

Difícil de definir, o texto apoia-se no (quase) melodrama, com um final de tragédia, mas também não abdica do necessário humor (beckettiano) que conota o que também poderá ser uma grande pochade. 0 que acontece nesses três actos além de uma espera, uma estadia num hotel e uma nova espera numa "clínica privada muito moderna"? Ironia do final, nesse último espaço ou território, é o inefável Dr. House, o portador das notícias de mortes por concluir, que nos faz assistir à inelutável progressão para a morte do corpo entubado, com um diagnóstico clínico profissional e competente, formulado comicamente na Canção do boletim clínico..

Nesse texto escrito a pedido do encenador Pedro Gil, e que, contrariamente aos seus textos precedentes, Jorge Silva Melo não encenou, é evidente a relevância dada ao texto que nos leva para o território fascinante de uma poética teatral amadurecida, que não deve nada a uma qualquer veia criativa ou ao acaso, mas tem a solidez de um imaginário teatral comprometido com um património literário, musical e fílmico multifacetado, ao mesmo tempo privado e partilhado/partilhável. E também é um desafio para a leitura (ou releitura) de textos, com o prazer da fruição desta fábrica do texto, no sentido material e instrumental que a língua Ihe dá.

Resulta num concerto de vozes - que podem ser as nossas também - perguntando pela juventude e pelo amor, por intermédio de personagens míticas, esquecidas numa Sala VIP de aeroporto.

Com o modo pessoal de recorrer à intertextualidade - que o dramaturgo adoptou desde a escrita de 0 fim -, a peça Sala VIP devolve para uma nova vida, pondo-os em cena, muitos outros textos, e nem todos pertencentes ao universo do teatro. Talvez o mais tocante seja o uso da Manon Lescaut. Esta narrativa edificante, escrita pelo Abade Prévost no séc. XVIII, além de sustentar a fábula da peça, é materializada ao longo do espectáculo na presença fisica da obra, num adereço talvez raro no teatro, num livro como objecto. A imagem impõe-se no vazio inicial

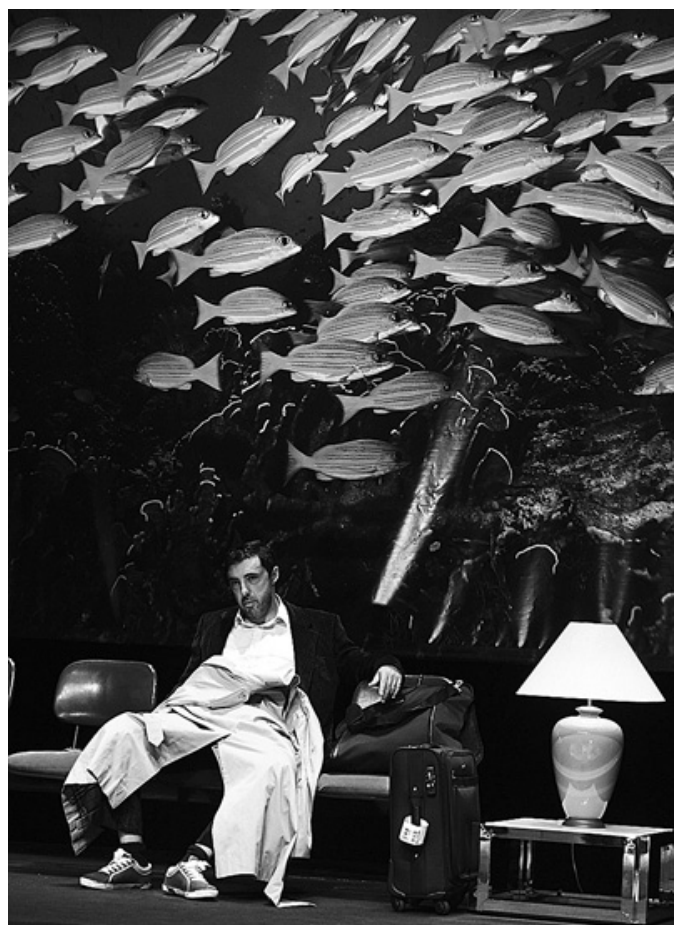

do palco em que, no primeiro plano, está no chão como adereço, antes de ser mais tarde ingrediente da acção: lêse e comenta-se, passa por várias mãos, e no final a morte da bela e jovem Manon, a infeliz pecadora do romance, termina o espectáculo, na versão operática de Puccini, passada num ecrã de TV, instalado no fundo do palco que se escurece pouco a pouco.

Desafio hermenêutico, a dramaturgia segundo Silva Melo continua a afirmar-se como prática do teatro, atenta ao lugar do texto, como vimos. Mas nesta obra deixa perceber o lugar da expressão privada de um desencanto na tonalidade mais nitidamente melancólica que conota o texto. Trata-se certamente de uma obra mais pessoal, servida por excelentes actores que pressentimos envolvidos numa encenação que soube dialogar com o universo criado por uma peça marcada pelo ar do tempo em que hoje vivemos. E que deixa uma interrogação. No final, Leonora pergunta: "O que é que tu dizes depois? | 0 que dizes quando a festa acabou? Depois do baile?" É forçoso perguntar também: "E depois de Sala VIP"... Será que o teatro pode ainda continuar a ser "A hora da fantasia que combate a melancolia..."?

\section{Referências bibliográficas}

MELO, Jorge Silva (1997), "O que ficou depois de quê?", in Prometeu. Rascunhos, Lisboa, \&t etc, pp.179-185.

-- (2001), "Ó noite mãe negra na casa dos Átridas", in O navio dos negros Lisboa, Livrinhos Cotovia, pp.11-15.

_- (2013), Sala VIP, Lisboa, Livrinhos Cotovia.

PORTO, Carlos (1996), "O fim e o principio", Jornal de letras, 23 de Outubro, p. 29

SERÔDIO, Maria Helena (2004), "Dramaturgia", in Literatura portuguesa do século XX, coord. Fernando J.B. Martinho, Lisboa, Instituto Camões, pp. 95-141. 